Check for updates

Cite this: RSC Adv., 2017, 7, 41903

Received 14th June 2017 Accepted 20th July 2017

DOI: $10.1039 / \mathrm{c} 7 \mathrm{ra06643k}$

rsc.li/rsc-advances

\title{
A facilely synthesized 'spiro' hole-transporting material based on spiro[3.3]heptane-2,6- dispirofluorene for efficient planar perovskite solar cells
}

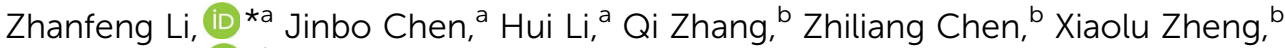 \\ Guojia Fang, (D) *b Hua wang ${ }^{c}$ and Yuying Hao*a
}

A low-cost spiro[3.3] heptane-2,6-dispirofluorene (SDF) based hole transporting material termed SDFOMeTAD has been designed and synthesized via a two-step reaction, representing a considerable simplification with respect to that of the well-known spiro-OMeTAD. The SDF-OMeTAD was exploited in lead halide planar perovskite solar cells using low-temperature solution-processed $\mathrm{SnO}_{2}$ as the electron transporting layer, delivering a competitive power conversion efficiency of $13.01 \%$ with an open-circuit voltage of $1.10 \mathrm{~V}$ under $100 \mathrm{~mW} \mathrm{~cm} \mathrm{~cm}^{-2}$ AM 1.5G solar illumination. The facile synthesis approach of SDFOMeTAD from commercially available starting materials will facilitate SDF-based molecules to be further exploited in thin film organic-inorganic perovskite solar cells and can be optimized to further enhance power conversion efficiency.

\section{Introduction}

Organic-inorganic metal halide perovskite solar cells (PSCs) have attracted great attention in the scientific community as well as the solar energy industry due to their extraordinary power conversion efficiencies (PCEs) soaring from an initial value of $3.8 \%$ to a certified $22.1 \%$ over the past few years. ${ }^{1-5}$ Perovskite materials have been successfully applied as light absorbers to thin or thick mesostructured and planar heterojunction architectures because of their excellent properties, including excellent optical properties, high charge carrier mobility, long diffusion length, long carrier lifetimes, and solution processability. ${ }^{6-8}$ In a typical PSC, the costly spiro-OMeTAD $\left(2,2^{\prime} 7,7^{\prime}\right.$-tertrakis( $N, N-p$-dimethoxyphenylamino)-9,9'-spirobifluorene) is generally used as the holetransporting material (HTM) to promote the rate of hole transfer for the excited perovskite, which demonstrates a low recombination rate and efficient charge transport improving the device performance. ${ }^{9}$ However, aside from its potential HTM features, the complex synthesis, high cost, and low charge carrier mobility of spiro-OMeTAD could impede its large-scale application in

${ }^{a}$ Key Laboratory of Advanced Transducers and Intelligent Control System, Ministry of Education and Shanxi Province, College of Physics and Optoelectronics, Taiyuan University of Technology, Taiyuan 030024, China. E-mail: lizhanfeng@tyut.edu.cn; haoyuying@tyut.edu.cn

${ }^{b}$ Key Laboratory of Artificial Micro- and Nano-structures of Ministry of Education of China, School of Physics and Technology, Wuhan University, Wuhan 430072, China. E-mail: gifang@whu.edu.cn

${ }^{c}$ Key Laboratory of Interface Science and Engineering in Advanced Materials, Taiyuan University of Technology, Taiyuan 030024, China
PSCs, since it includes five reaction steps that requires low temperature $\left(-78^{\circ} \mathrm{C}\right)$, and sensitive ( $n$-butyllithium or Grignard reagents) and aggressive $\left(\mathrm{Br}_{2}\right)$ reagents with a total yield of less than $30 \% .^{10}$ In addition, high-purity sublimation-grade spiroOMETAD is required to obtain high-performance devices. ${ }^{11}$ Therefore, it is highly desirable to develop low cost, and more straightforward routes of synthesis to render highly efficient small-molecule HTMs as alternatives to spiro-OMeTAD in solar cell application. ${ }^{11-30}$ In this respect, many kinds of molecular HTMs afforded by facile synthetic steps from commercially available raw materials were recently developed and tested in PSCs, e.g., methoxydiphenylamine-substituted carbazole, ${ }^{11,12}$ difluorobenzene, ${ }^{13}$ biphenyl, ${ }^{12}$ pyrene ${ }^{14}$ spiro-based derivatives, ${ }^{15-20}$ tetraphenylethenederivative, ${ }^{21}$ dioxythiophene, ${ }^{22,23}$ and triphenylamine. ${ }^{29}$ Specifically, a simple difluorobenzene-core arylamine hole conductor (DFTAB) via only one synthetic step from inexpensive starting materials was designed as HTM for PSCs and a stabilized PCE of $10.4 \%$ was obtained. ${ }^{13}$

Here we presented a molecularly engineered HTM 4,4'dimethoxydiphenylamine-substituted spiro[3.3]heptane-2,6dispirofluorene (SDF-OMeTAD) for PSCs. The novel HTM did not require an expensive synthetic procedure and was prepared employing a straightforward two-step strategy. Devices with a typical planar configuration of $\mathrm{FTO} / \mathrm{SnO}_{2} / \mathrm{CH}_{3} \mathrm{NH}_{3} \mathrm{PbI}_{3} / \mathrm{SDF}$-OMeTAD/Au afforded an average PCE of $10.33 \%$ with an open-circuit voltage of $1.10 \mathrm{~V}$ under $100 \mathrm{~mW} \mathrm{~cm}^{-2} \mathrm{AM} 1.5 \mathrm{G}$ solar illumination. The reference HTM (spiro-OMeTAD), under the same testing conditions, displayed a PCE of $15.50 \%$. In particular, the SDF-OMeTAD-based 
devices have exhibited remarkable device performance with maximum PCE of $13.01 \%$.

\section{Experimental section}

\subsection{Materials}

4-tert-Butylpyridine (TBP) and Li-bis(trifluoromethanesulfonyl) imide (LiTFSI) were purchased from Aladdin-reagent. Lead iodide $\left(\mathrm{PbI}_{2}\right)$ (99.99\%), hydroiodic acid (57 wt\% in water, 99.99\%), and methylamine (33 wt\% in absolute ethanol) were purchased from Sigma-Aldrich. Spiro-OMeTAD ( $\geq 99.0 \%)$ was purchased from Shenzhen Feiming Science and Technology Co., Ltd. Fluorine-doped tin oxide (FTO) glass with a sheet resistance of $14 \Omega \mathrm{sq}^{-1}$ was purchased from Asahi Glass (Japan). The purity of gold wire was $99.99 \%$. Other reagents were used as received from commercial sources. The manipulation involving air-sensitive reagents was performed under an inert atmosphere of dry nitrogen.

\subsection{Synthesis}

The synthesis of compound SDF-OMeTAD was obtained by Buchwald-Hartwig reaction in which 4,4'-dimethoxydiphenylamine ( $3.44 \mathrm{~g}, 15.00 \mathrm{mmol}), 4 \mathrm{Br}-\mathrm{SDF}(1.785 \mathrm{~g}, 2.50 \mathrm{mmol})$, and $\mathrm{NaO}^{t-} \mathrm{Bu}(1.73 \mathrm{~g}, 18.00 \mathrm{mmol})$ were added to $20 \mathrm{~mL}$ of dry toluene. The system was purged with nitrogen several times. Then tris(dibenzylideneacetone)dipalladium $(0.685 \mathrm{~g}$, $0.75 \mathrm{mmol})$ and tritertbutylphosphine $(0.455 \mathrm{~g}, 2.25 \mathrm{mmol})$ were placed in mixture solution and reaction was refluxed overnight under nitrogen atmosphere. After cooling to room temperature, the reaction mixture was extracted with ethyl acetate and the organic phases were dried with anhydrous $\mathrm{MgSO}_{4}$. After the solvent was evaporated, the residue was purified by column chromatography (dichloromethane/hexane $=2 / 1$ ) to afford $2.60 \mathrm{~g}$ (yield $80 \%$ ) of SDF-OMeTAD. ${ }^{1} \mathrm{H}$ NMR $\left(400 \mathrm{MHz}, \mathrm{CDCl}_{3}\right)$ $\delta: 7.21-6.50(\mathrm{~m}, 32 \mathrm{H}), 3.76(\mathrm{~d}, J=28.7 \mathrm{~Hz}, 24 \mathrm{H}), 2.56-2.34(\mathrm{~m}$, $8 \mathrm{H}), 1.61(\mathrm{~s}, 4 \mathrm{H}), 1.25(\mathrm{~s}, 4 \mathrm{H}), 0.94-0.82(\mathrm{~m}, 4 \mathrm{H})$. Anal. calcd $(\%)$ for $\mathrm{C}_{87} \mathrm{H}_{76} \mathrm{~N}_{4} \mathrm{O}_{8}$ : C, 80.02; H, 5.87. Found: C, 79.92; H, 5.81 .

\subsection{Characterization}

${ }^{1} \mathrm{HNMR}$ was recorded on a Bruker $400 \mathrm{MHz}$ NMR spectrometer. Thermogravimetric analysis (TGA) and differential scanning calorimetry (DSC) were carried on a STA 409 PC instrument at a heating rate of $10{ }^{\circ} \mathrm{C} \mathrm{min}^{-1}$ under nitrogen. Absorption spectra were recorded by a Unico UV-2600 PCS spectrophotometer. Cyclic voltammetry (CV) was performed using a CHI 660E electrochemical workstation at a scan rate of $100 \mathrm{mV} \mathrm{s}^{-1}$. All experiments were carried out in a three-electrode compartment cell with a Pt-sheet counter electrode, a glassy carbon working electrode, and a Pt-wire reference electrode. The supporting electrolyte was $0.1 \mathrm{M}$ tetrabutylammonium hexafluorophosphate $\left(\mathrm{Bu}_{4} \mathrm{NPF}_{6}\right)$ solution in dry acetonitrile. The cell containing the solution of the sample $(1 \mathrm{mM})$ and the supporting electrolyte was purged with a nitrogen gas thoroughly before scanning for its oxidation and reduction properties. Ferrocene was used for potential calibration in each measurement. All the potentials were reported relative to ferrocene-ferrocenium $\left(\mathrm{Fc} / \mathrm{Fc}^{+}\right)$couple, whose oxidation potential was $+0.13 \mathrm{~V}$ relative to the reference electrode. Density functional theory (DFT) calculations (B3LYP) were performed for the target compound with the $6-31 \mathrm{G}(\mathrm{d}, \mathrm{p})$ basis set by using the Gaussian 09 program.

\subsection{Device fabrication and performance measurement}

FTO glass was patterned and cleaned sequentially with ethanol and acetone in an ultrasonic cleaner. $\mathrm{SnO}_{2}$ thin layers were prepared by spin-coating precursor solutions of $0.1 \mathrm{M} \mathrm{SnCl}_{2}-$ $\cdot 2 \mathrm{H}_{2} \mathrm{O}$ in ethanol on clean FTO substrates, followed by annealing at $180{ }^{\circ} \mathrm{C}$ for 1 hour in the air. The perovskite $\mathrm{CH}_{3} \mathrm{NH}_{3} \mathrm{PbI}_{3}$ films were prepared by a two-step method. Firstly, $462 \mathrm{mg} \mathrm{\textrm {PbI } _ { 2 }}$ dissolved in $1 \mathrm{~mL}$ dimethylformamide was stirred at $70{ }^{\circ} \mathrm{C}$ overnight. The solution was spin-coated on the FTO substrates with $\mathrm{SnO}_{2}$ thin layers at a low speed of 500 r.m.p. for $3 \mathrm{~s}$ and followed a high speed of 2000 r.m.p for 30 s. Secondly, the substrates were dipped into $10 \mathrm{mg} \mathrm{mL}^{-1} \mathrm{CH}_{3} \mathrm{NH}_{3}$ I dissolved in isopropanol for $8 \mathrm{~min}$ and then dipped into clean isopropanol at room temperature. Finally, the films were heated in air at $70{ }^{\circ} \mathrm{C}$ for $0.5 \mathrm{~h}$. To complete the devices, the perovskite films was spin-coated with hole-transport layers (HTLs) using a solution composed of $68 \mathrm{mM}$ HTM (spiro-OMeTAD or SDF-OMeTAD), $26 \mathrm{mM}$ LiTFSI, and $55 \mathrm{mM}$ TBP dissolved in acetonitrile and chlorobenzene $(\mathrm{v} / \mathrm{v}=1: 10)$ and then evaporated with thin gold electrodes. The current-voltage $(J-V)$ characteristics were performed on a CHI660D electrochemical workstation (ShangHai, China). The masked active area of the device is $0.09 \mathrm{~cm}^{2}$. All the cells were measured under a $100 \mathrm{~mW} \mathrm{~cm} \mathrm{c}^{-2}$ (AM1.5 simulated irradiation) illumination with a standard ABET Sun 2000 Solar Simulator. A standard silicon solar cell was used to calibrate the light intensity. Scanning electron microscopy (SEM) images were obtained with Jeol JSM-7100F.

\section{Results and discussion}

The synthetic route towards SDF-OMeTAD only requires two steps from inexpensive commercial precursors (Scheme 1). The 4Br-SDF was synthesized by one-pot reaction using commercial available 2,7-dibromofluorene and pentaerythrityl tetrabromide as the starting materials, and no column chromatography was needed for the purification, while the low reactivity of spirobifluorene (SBF) of spiro-OMeTAD made it challenging to finish bromination thoroughly and several multibrominated products coexist, resulting in low yield and tedious purification steps subsequently. ${ }^{10}$ Then a palladium-catalyzed Buchwald-Hartwig $\mathrm{C}-\mathrm{N}$ cross-coupling reaction was utilized to obtain the target compound SDF-OMeTAD having the conjugation-uninterrupted branching point, ${ }^{31}$ which mimics SBF moiety of well-studied spiro-OMeTAD. SDF-OMeTAD has good solubility in common organic solvents such as dichloromethane, chloroform, chlorobenzene, and toluene, which was beneficial for solution processing.

Material cost estimation for the synthesis of SDF-OMeTAD has been performed following the procedure established by Osedach et $_{\text {al. }}{ }^{32}$ It was reported that the SBF core and the Pdcatalysed coupling are the main influence on the final price of 
the material, where the synthesis cost of SBF (ranging from 35 to $44 \mathrm{~S} \mathrm{~g}^{-1}$ ) is responsible for about half of the final cost of spiro-OMeTAD (from 92 to $108 \mathrm{~S} \mathrm{~g}^{-1}$ ). ${ }^{25}$ Therefore, the introduction of SDF core as an inexpensive alternative (costing about $1.5 \mathrm{~S} \mathrm{~g}^{-1}$ ) cuts the cost of the final material to half and decreases the number of steps from 5 for spiro-OMeTAD to 2 for SDFOMeTAD, which is promising for mass production. ${ }^{23}$ The estimated synthesis cost of SDF-OMeTAD is $\sim 18 \mathrm{~S} \mathrm{~g}^{-1}$ which is less than one fifth the cost of the reference HTM, spiro-OMeTAD. And no air sensitive, corrosive or toxic reagents need to be used during the synthesis of SDF-OMeTAD. Additionally, the amount of chemical waste as a result of the intensive purification for Spiro-OMeTAD is significantly higher than for SDFOMeTAD, which not only has a large impact on the cost, but also on the environment. ${ }^{32}$

UV-Vis absorption spectra of SDF-OMeTAD and spiroOMeTAD in $\mathrm{CH}_{2} \mathrm{Cl}_{2}$ are shown in Fig. 1(a). Similar to the spiro-OMeTAD, SDF-OMeTAD exhibits intense absorption at $395 \mathrm{~nm}$ and a weak one at $311 \mathrm{~nm}$, which can be attributed to their highly related chemical structure. Both the spiro-type molecules display weak absorption at the visible light region because of the twisted conformation and the conjugation interception by the spiro center, ${ }^{15-19,33}$ which are the desired optical properties for a HTM layer in PSCs. The band gap energy is determined to be $2.99 \mathrm{eV}$ for SDF-OMeTAD, which is very close to that of spiro-OMeTAD. The result of thermo gravimetric analysis (TGA) in Fig. 1(b) shows that SDF-OMeTAD has an exceptional thermal decomposition temperature $\left(T_{\mathrm{d}}\right)$ of up to $400{ }^{\circ} \mathrm{C}$, which is comparable with that of spiro-OMeTAD. ${ }^{34,35}$ Thus, the new spiro[3.3] heptane-2,6-dispirofluorene core almost has no influence on the light-induced electronic transition or thermal stability of spiro-type HTM.

To investigate the potential application of the SDF-OMeTAD as HTMs in PSCs, we calculated the energy levels and the corresponding Frontier orbital distributions using density functional theory method with Gaussian09 program package at the B3LYP/6-31G(d,p) level. As shown in Fig. 2, the SDF-OMeTAD molecule adopts a three-dimensional conformation because of the SDF core, and the dihedral angle of the two fluorine planes of SDF is about $60^{\circ}$. The distance of the conjugationuninterrupted branching point of the SDF core is about $4.2 \AA$. These are the most likely reason for their high solubility in most

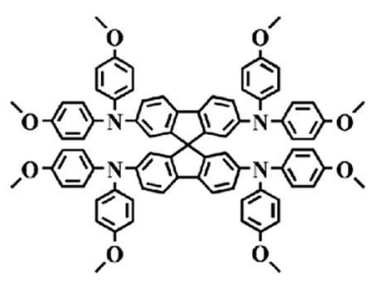

spiro-OMeTAD

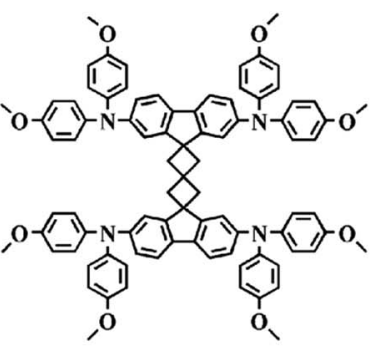

SDF-OMETAD
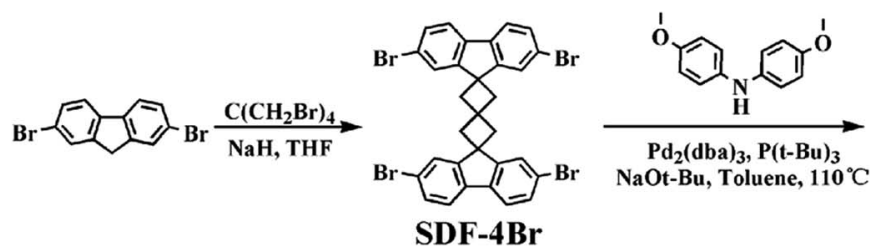

$\mathbf{P d}_{2}(\mathrm{dba})_{3}, \mathbf{P}(\mathrm{t}-\mathrm{Bu})_{3}$ $\mathrm{NaOt}-\mathrm{Bu}$, Toluene, $110^{\circ} \mathrm{C}$

\section{SDF-OMETAD}

SDF-4Br

(a)

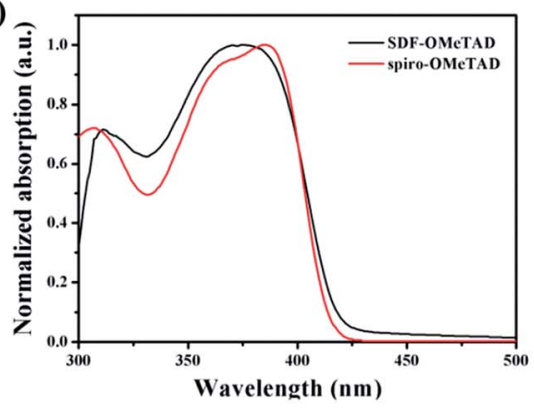

(b)

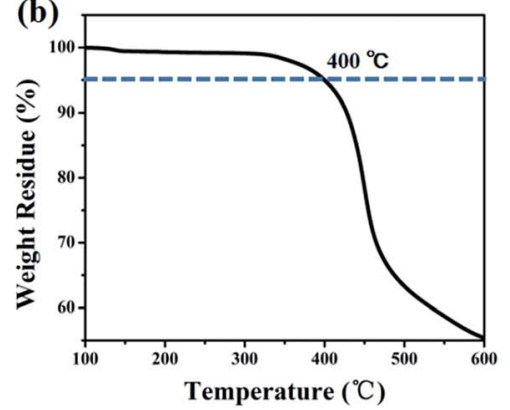

Fig. 1 (a) UV-Vis spectra of SDF-OMeTAD and spiro-OMeTAD in $\mathrm{CH}_{2} \mathrm{Cl}_{2}$. (b) TGA curve of SDF-OMeTAD with a scan rate of $10{ }^{\circ} \mathrm{C}$ min ${ }^{-1}$ under a nitrogen atmosphere. 

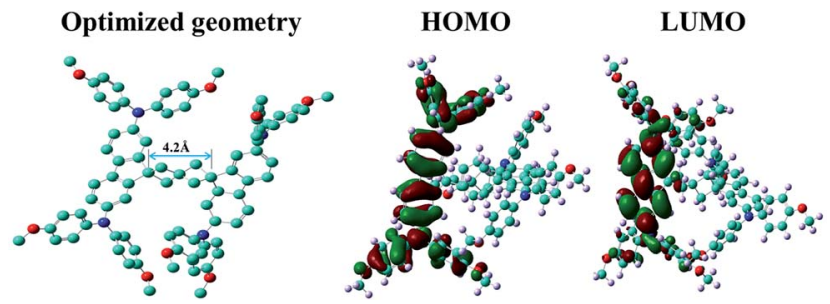

Fig. 2 Optimized molecular conformation and Frontier molecular orbitals of SDF-OMeTAD calculated using Gaussian (B3LYP/6-31G(d)).

commonly used organic solvents. The highest occupied molecular orbital (HOMO) is delocalized over the half backbone of the molecule, whereas the lowest unoccupied molecular orbital (LUMO) spreads mainly over the central fluorene core of one half. Hence, the partial wave function overlap between HOMO and LUMO orbitals is expected to be beneficial for the fast formation of neutral excitons and hole-transfer transitions. $^{36}$ The calculated energy level is $-4.17 \mathrm{eV}$ for HOMO and $-0.58 \mathrm{eV}$ for LUMO, respectively, indicating that the SDFOMeTAD is suitable for the PSCs as a kind of HTM.

We also determine the HOMO and LUMO energy levels experimentally by cyclic voltammetry (CV) using ferrocene/ ferrocenium as an internal standard. The diagram of CV curve is shown in Fig. 3(a) and the corresponding energy level is depicted in Fig. 3(b). The HOMO energy level of SDF-OMeTAD is at $-5.28 \mathrm{eV}$, i.e., slightly deeper than that of spiro-OMeTAD $(-5.22 \mathrm{eV})$ but better matched with the valence band of $\mathrm{CH}_{3} \mathrm{NH}_{3} \mathrm{PbI}_{3}$ perovskite $(-5.43 \mathrm{eV}) .^{37}$ It confirms that SDFOMeTAD is suitable for effective hole extraction from the $\mathrm{CH}_{3} \mathrm{NH}_{3} \mathrm{PbI}_{3}$-based PSCs. The LUMO level of $-2.37 \mathrm{eV}$ is estimated according to its HOMO energy and optical bandgap, which will allow sufficient offset of the conduction band of perovskite to block the electrons from perovskite and thus suppress charge recombination (Fig. 3(b)). ${ }^{38,39}$

The devices with a typical planar configuration of $\mathrm{FTO} / \mathrm{SnO}_{2} /$ $\mathrm{CH}_{3} \mathrm{NH}_{3} \mathrm{PbI}_{3} / \mathrm{HTL} / \mathrm{Au}$ were fabricated to evaluate the efficacy of the newly synthesized SDF-OMeTAD as HTM, wherein highly crystalline $\mathrm{SnO}_{2}$ nanocrystals were used as an efficient electrontransporting layer (ETL) fabricated by following our recent work. ${ }^{40}$ The $\mathrm{SnO}_{2}$ ETLs were synthesized by a facile solution approach spin-coating of $\mathrm{SnCl}_{2} \cdot 2 \mathrm{H}_{2} \mathrm{O}$ precursor prepared at

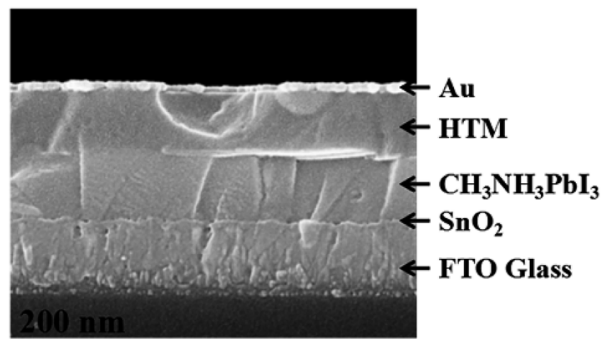

Fig. 4 Cross-sectional SEM image of the $\mathrm{CH}_{3} \mathrm{NH}_{3} \mathrm{Pbl}_{3} / \mathrm{HTM}$ planar photovoltaic cell with SDF-OMeTAD as the HTM layer.

a room temperature and followed by thermal annealing in air. Our low-temperature solution-processed $\mathrm{SnO}_{2}$ films had a nanocrystalline in nature, which enabled smooth and conformal coating of the $\mathrm{SnO}_{2}$ thin layers on the FTO substrates. The perovskite layers were prepared according to our optimized sequential two-step solution method. ${ }^{\mathbf{4}}$ Holetransport layers (HTLs) were deposited under an inert atmosphere $\left(\mathrm{N}_{2}\right)$ on the perovskite layer by spin-coating a chlorobenzene solution of the HTM, LiTFSI, and TBP. The cells fabricated using spiro-OMeTAD as the HTM under similar conditions was also tested for comparison. Finally, the devices were completed by the evaporation of the gold electrode. Clear interfaces in the device structure are observed in the crosssectional scanning electron microscopy (SEM) image (Fig. 4). The thicknesses of the $\mathrm{SnO}_{2} / \mathrm{CH}_{3} \mathrm{NH}_{3} \mathrm{PbI}_{3}$ layer and the $\mathrm{Au}$ electrode were $\sim 260 \mathrm{~nm}$ and $\sim 40 \mathrm{~nm}$, respectively, whereas those of the HTM layers were varied in the range of $240 \mathrm{~nm}$ to obtain the optimum device performance.

The current density-voltage $(J-V)$ curves measured under $100 \mathrm{~mW} \mathrm{~cm}{ }^{-2}$ AM1.5G illumination were shown in Fig. 5(a) and the relevant photovoltaic data of the devices were summarized in Table 1. Devices fabricated with SDF-OMeTAD + TBP + LiTFSI exhibited an average PCE of $>10 \%$. This initial performance was lower however than the $15.50 \%$ with the same device fabrication procedure using spiro-OMeTAD, although, in mitigation, process optimization of spiro-OMeTAD was much more understood. The champion device with SDF-OMeTAD provided an open-circuit voltage $\left(V_{\mathrm{oc}}\right)$ of $1.10 \mathrm{~V}$, a short-circuit current density $\left(J_{\mathrm{sc}}\right)$ of $19.06 \mathrm{~mA} \mathrm{~cm} \mathrm{~cm}^{-2}$ and a fill factor (FF) of $62 \%$,
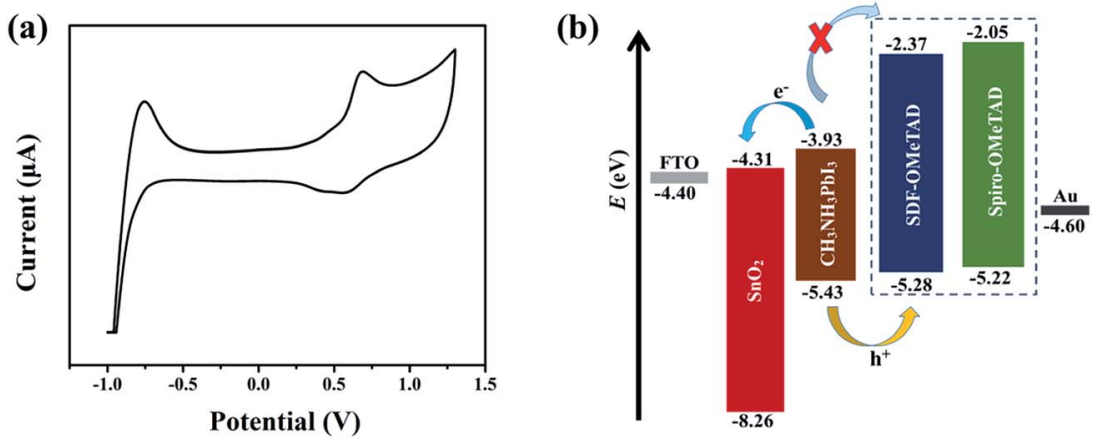

Fig. 3 (a) Cyclic voltammogram in acetonitrile for SDF-OMeTAD. (b) Energy level diagram of the corresponding materials used in the investigated devices. 
(a)

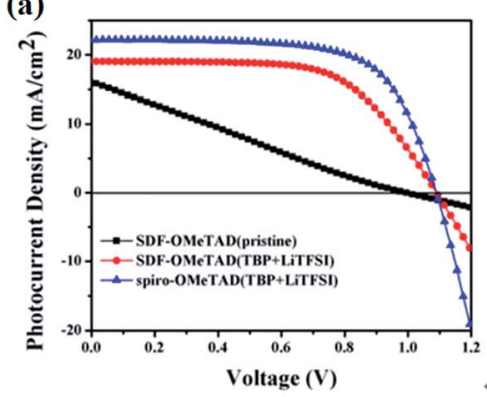

(b)

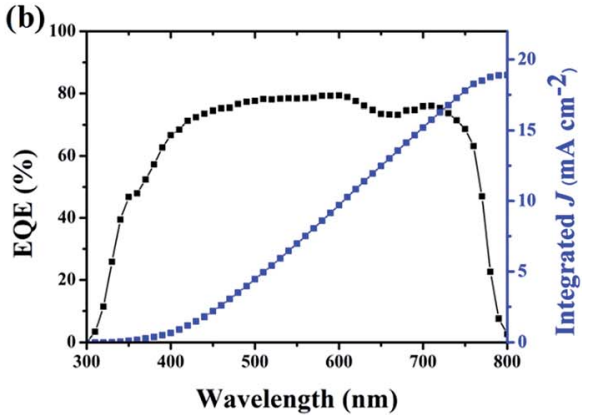

Fig. 5 (a) Current $(\mathrm{J})$-voltage $\left(V\right.$ curves of the solar cells with SDF-OMeTAD and spiro-OMeTAD under AM $1.5 \mathrm{conditions}^{(100} \mathrm{mW} \mathrm{cm}^{-2}$ ). (b) EQE spectra of $\mathrm{CH}_{3} \mathrm{NH}_{3} \mathrm{Pbl}_{3} / \mathrm{SDF}-\mathrm{OMeTAD}$ perovskite solar cell.

Table 1 Photovoltaic parameters of PSCs using SDF-OMeTAD and spiro-OMeTAD as HTMs

\begin{tabular}{llllrr}
\hline HTMs & Additives & $J_{\mathrm{sc}}\left(\mathrm{mA} \mathrm{cm}^{-2}\right)$ & $V_{\text {oc }}(\mathrm{V})$ & FF $(\%)$ & PCE $(\%)$ \\
\hline SDF-OMeTAD & TBP + LiTFSI & 19.06 & 1.10 & 62 & 13.01 \\
SDF-OMeTAD & - & 19.02 & 1.01 & 25 & 4.83 \\
Spiro-OMeTAD & TBP + LiTFSI & 22.03 & 1.11 & 69 & 10.33 \\
Spiro-OMeTAD & - & 17.31 & 1.00 & 25 & 17.13 \\
\end{tabular}

${ }^{a}$ The average values are calculated from 16 devices.

affording an overall PCE of 13.01\%. Compared with the cell derived from spiro-OMeTAD, which exhibited a PCE of $17.13 \%$ with a $J_{\mathrm{sc}}$ of $22.03 \mathrm{~mA} \mathrm{~cm} \mathrm{~cm}^{-2}$, a $V_{\mathrm{oc}}$ of $1.11 \mathrm{~V}$, and a $\mathrm{FF}$ of $69 \%$, the SDF-OMeTAD-based cell was quite similar in terms of the $V_{\mathrm{oc}}$, but the $J_{\mathrm{sc}}$ and $\mathrm{FF}$ were slightly lower. Photovoltaic devices were also fabricated without additional additives. In the absence of dopants SDF-OMeTAD based devices generated a PCE of only $4.83 \%$ due to the significant lowering of $\mathrm{FF}$, and the reference dopant-free spiro-OMeTAD-based device exhibited a slightly lower PCE of $4.27 \%$. Significant improvements can be expected after further optimization of the processing conditions. The incident photon to current conversion efficiency spectra of the PSC based on SDF-OMeTAD HTM is shown in Fig. 5(b). The device exhibits a wide response from the visible to the nearinfrared region, with the external quantum efficiency (EQE) values over $70 \%$ ranging from 470 to $620 \mathrm{~nm}$, and from 690 to $720 \mathrm{~nm}$. The maximum intensity of EQE spectra obtained at about $600 \mathrm{~nm}$ for the SDF-OMeTAD device exceeds $80 \%$. The calculated photocurrent from the EQE spectrum is $18.80 \mathrm{~mA} \mathrm{~cm}^{-2}$ that agrees well with the measured $J_{\mathrm{sc}}$.

To investigate the long-term stability of devices containing either SDF-OMeTAD or spiro-OMeTAD as HTM, we also monitored the long-term stability of PSCs without encapsulation and under identical storage conditions (in a dry box). ${ }^{\mathbf{4 1}}$ Preliminary stability tests indicate that the PSCs made with SDF-OMeTAD and spiro-OMeTAD have similar stability with about $10 \%$ of efficiency loss after 1000 hours.

\section{Conclusions}

In conclusion, we reported a novel easily attainable SDF-based HTM named SDF-OMeTAD, obtained by a straightforward two-step synthetic route from commercially available and inexpensive starting materials. Our preliminary results on perovskite devices fabricated using SDF-OMeTAD gave an impressive PCE of up to $13.01 \%$. Our study demonstrates that SDF-OMeTAD with reduced cost and reduced environmental impact compared to state-of-the-art HTMs is very promising for mass production. Device engineering and optimization of the processing conditions to further improve energy conversion efficiencies is currently under investigation in our laboratory.

\section{Acknowledgements}

We are grateful for support from the National High Technology Research and Development Program ("863" Program) of China (2015AA016901), National Natural Scientific Foundation of China (Grant no. 61571317, 61308093, and 61475109), China Postdoctoral Science Foundation (Grant no. 2015M572454), Key Research and Development (International Cooperation) Program of Shanxi (201603D421042), and Platform and Base Special Project of Shanxi (201605D131038).

\section{References}

1 A. Kojima, K. Teshima, Y. Shirai and T. Miyasaka, J. Am. Chem. Soc., 2009, 131, 6050-6051.

2 T. Jesper Jacobsson, J. P. Correa-Baena, M. Pazoki, M. Saliba, K. Schenk, M. Grätzel and A. Hagfeldt, Energy Environ. Sci., 2016, 9, 1706-1724.

3 W. S. Yang, J. H. Noh, N. J. Jeon, Y. C. Kim, S. Ryu, J. Seo and S. I. Seok, Science, 2015, 348, 1234-1237.

4 D. Bi, W. Tress, M. I. Dar, P. Gao, J. Luo, C. Renevier, K. Schenk, A. Abate, F. Giordano, J.-P. Correa Baena, 
J. D. Decoppet, S. M. Zakeeruddin, M. K. Nazeeruddin, M. Grätzel and A. Hagfeldt, Sci. Adv., 2016, 2, e1501170.

5 Research Cell Efficiency Records, NREL, http://www.nrel.gov/ ncpv/, accessed, April 2016.

6 L. Etgar, P. Gao, Z. Xue, Q. Peng, A. K. Chandiran, B. Liu, M. K. Nazeeruddin and M. Grätzel, J. Am. Chem. Soc., 2012, 134, 17396-17399.

7 S. D. Stranks, G. E. Eperon, G. Grancini, C. Menelaou, M. J. P. Alcocer, T. Leijtens, L. M. Herz, A. Petrozza and H. J. Snaith, Science, 2013, 342, 341-344.

8 G. Xing, N. Mathews, S. Sun, S. S. Lim, Y. M. Lam, M. Grätzel, S. Mhaisalkar and T. C. Sum, Science, 2013, 342, 344-347.

9 D. Bi, L. Yang, G. Boschloo, A. Hagfeldt and E. M. J. Johansson, J. Phys. Chem. Lett., 2013, 4, 1532-1536.

10 T. P. I. Saragi, T. Spehr, A. Siebert, T. Fuhrmann-Lieker and J. Salbeck, Chem. Rev., 2007, 107, 1011-1065.

11 P. Gratia, A. Magomedov, T. Malinauskas, M. Daskeviciene, A. Abate, S. Ahmad, M. Grätzel, V. Getautis and M. K. Nazeeruddin, Angew. Chem., Int. Ed., 2015, 54, 11409-11413.

12 J. Y. Shao, D. Li, K. Tang, Y. W. Zhong and Q. B. Meng, RSC Adv., 2016, 6, 92213-92217.

13 H. Chen, D. Bryant, J. Troughton, M. Kirkus, M. Neophytou, X. Miao, J. R. Durrant and I. McCulloch, Chem. Mater., 2016, 28, 2515-2518.

14 N. J. Jeon, J. Lee, J. H. Noh, M. K. Nazeeruddin, M. Grätzel and S. I. Seok, J. Am. Chem. Soc., 2013, 135, 19087-19090.

15 K. Rakstys, M. Saliba, P. Gao, P. Gratia, E. Kamarauskas, S. Paek, V. Jankauskas and M. K. Nazeeruddin, Angew. Chem., Int. Ed., 2016, 55, 7464-7468.

16 B. Xu, D. Bi, Y. Hua, P. Liu, M. Cheng, M. Grätzel, L. Kloo, A. Hagfeldt and L. Sun, Energy Environ. Sci., 2016, 9, 873-877.

17 T. Malinauskas, M. Saliba, T. Matsui, M. Daskeviciene, S. Urnikaite, P. Gratia, R. Send, H. Wonneberger, I. Bruder, M. Grätzel, V. Getautis and M. K. Nazeeruddin, Energy Environ. Sci., 2016, 9, 1681-1686.

18 D. Bi, B. Xu, P. Gao, L. Sun, M. Grätzel and A. Hagfeldt, Nano Energy, 2016, 23, 138-144.

19 Y. Hua, J. Zhang, B. Xu, P. Liu, M. Cheng, L. Kloo, E. M. J. Johansson, K. Sveinbjörnsson, K. Aitola, G. Boschloo and L. Sun, Nano Energy, 2016, 26, 108-113.

20 Y. Shi, Y. Xue, K. Hou, G. Meng, K. Wang, R. Chi, F. Chen, H. Ren, M. Pang and C. Hao, RSC Adv. , 2016, 6, 96990-96996. 21 F. Wu, B. Wang, R. Wang, Y. Shan, D. Liu, K. Y. Wong, T. Chen and L. Zhu, RSC Adv., 2016, 6, 69365-69369.

22 H. Li, K. Fu, A. Hagfeldt, M. Grätzel, S. G. Mhaisalkar and A. C. Grimsdale, Angew. Chem., Int. Ed., 2014, 53, 4085-4088.
23 M. L. Petrus, T. Bein, T. J. Dingemans and P. Docampo, J. Mater. Chem. A, 2015, 3, 12159-12162.

24 H. Choi, S. Park, S. Paek, P. Ekanayake, M. K. Nazeeruddin and J. Ko, J. Mater. Chem. A, 2014, 2, 19136-19140.

25 M. Maciejczyk, A. Ivaturi and N. Robertson, J. Mater. Chem. A, 2016, 4, 4855-4863.

26 A. T. Murray, J. M. Frost, C. H. Hendon, C. D. Molloy, D. R. Carbery and A. Walsh, Chem. Commun., 2015, 51, 8935-8938.

27 J. Wang, Y. Chen, M. Liang, G. Ge, R. Zhou, Z. Sun and S. Xue, Dyes Pigm., 2016, 125, 399-406.

28 H. Choi, H. M. Ko and J. Ko, Dyes Pigm., 2016, 126, 179-185.

29 A.-N. Cho, H.-S. Kim, T.-T. Bui, X. Sallenave, F. Goubard and N.-G. Park, RSC Adv., 2016, 6, 68553-68559.

30 X. Liu, F. Kong, Z. Tan, T. Cheng, W. Chen, T. Yu, F. Guo, J. Chen, J. Yao and S. Dai, RSC Adv., 2016, 6, 87454-87460.

31 Y. Wu, J. Li, W. Liang, J. Yang, J. Sun, H. Wang, X. Liu, B. Xu and W. Huang, New J. Chem., 2015, 39, 5977-5983.

32 T. P. Osedach, T. L. Andrew and V. Bulović, Energy Environ. Sci., 2013, 6, 711-718.

33 X. Liang, K. Wang, R. Zhang, K. Li, X. Lu, K. Guo, H. Wang, Y. Miao, H. Xu and Z. Wang, Dyes Pigm., 2017, 139, 764-771.

34 T. Leijtens, I. K. Ding, T. Giovenzana, J. T. Bloking, M. D. McGehee and A. Sellinger, ACS Nano, 2012, 6, 14551462.

35 D. Tomkute-Luksiene, M. Daskeviciene, T. Malinauskas, V. Jankauskas, R. Degutyte, R. Send, N. G. Pschirer, H. Wonneberger, I. Bruder and V. Getautis, RSC Adv., 2016, 6, 60587-60594.

36 A. Krishna, D. Sabba, H. R. Li, J. Yin, P. P. Boix, C. Soci, S. G. Mhaisalkar and A. C. Grimsdale, Chem. Sci., 2014, 5, 2702-2709.

37 H. S. Kim, C. R. Lee, J. H. Im, K. B. Lee, T. Moehl, A. Marchioro, S. J. Moon, R. Humphry-Baker, J. H. Yum, J. E. Moser, M. Gräzel and N. G. Park, Sci. Rep., 2012, 2, 591-597.

38 Y. Xiao, G. Han, J. Wu and J. Y. Lin, J. Power Sources, 2016, 306, 171-177.

39 Y. K. Wang, Z. C. Yuan, G. Z. Shi, Y. X. Li, Q. Li, F. Hui, B. Q. Sun, Z. Q. Jiang and L. S. Liao, Adv. Funct. Mater., 2016, 26, 1375-1381.

40 W. Ke, G. Fang, Q. Liu, L. Xiong, P. Qin, H. Tao, J. Wang, H. Lei, B. Li, J. Wan, G. Yang and Y. Yan, J. Am. Chem. Soc., 2015, 137, 6730-6733.

41 J. He, C.-F. Ng, K. Y. Wong, W. Liu and T. Chen, ChemPlusChem, 2016, 81, 1292-1298. 